\title{
Forehead Osteoma Excision by Anterior Hairline Incision with Subcutaneous Dissection
}

Jun Sik Kim, Jeong Hwan Lee, Nam Gyun Kim, Kyung Suk Lee

Department of Plastic and Reconstructive Surgery, Institute of Health Sciences, Gyeongsang National University Hospital, Gyeongsang National University School of Medicine, Jinju, Korea

No potential conflict of interest relevant to this article was reported.

\begin{abstract}
Forehead osteomas are benign but can pose aesthetic and functional problems. These osteomas are resected via bicoronal or endoscopic approach. However, large osteomas cannot be removed via endoscopic approach, and bicoronal approach can result in damage to the supraorbital nerve with resultant numbness in the forehead. We present a new approach to resection of forehead osteomas, with access provided by an anterior hairline incision and subcutaneous dissection. Three patients underwent resection of the forehead osteoma through an anterior hairline incision. The dissection was carried in the subcutaneous plane, and the frontalis muscle and periosteum were divided parallel to the course of supraorbital nerve. The resulting bony defect was re-contoured using Medpor $^{\circledR}$. All three patients recovered without any postoperative infection or complication and symptoms. Scalp sensory was preserved. Aesthetic outcomes were satisfactory. Patients remain free of recurrence for 12 months of follow up. The anterior hair line approach with subcutaneous dissection is an effective method for removal of forehead osteoma, since it offers broad visualization and hides the scar in the hairline. In addition, the dissection in the subcutaneous plane avoids inadvertent injury to the deep nerve branches and helps to maintains scalp sensation.
\end{abstract}

Keywords: Forehead / Osteoma / Dissection

\section{INTRODUCTION}

Most osteomas can be removed by incising the overlying skin along the relaxed skin tension line and excising the exposed tumor. However, this conventional approach is inappropriate for those osteomas located in a conspicuous location. For this reason, forehead osteomas are removed via the bicoronal approach with subgaleal dissection or endoscopic surgery. Endoscopic surgery is minimally invasive but cannot be used for removal of large masses. The bicoronal approach offers broad visualization and hides the incisional scar behind the hairline but may expose the deep

Correspondence: Jun Sik Kim

Department of Plastic and Reconstructive Surgery, Institute of Health Science, Gyeongsang National University Hospital, Gyeongsang National University College of Medicine, 79 Gangnam-ro, Jinju 52727, Korea

E-mail: kjuns@hanmail.net

Received October 9, 2015 / Revised December 10, 2015 / Accepted January 26, 2016 branch of supraorbital nerve to injury [1,2]. In this ideas paper, we present three cases of frontal osteomas removed via an anterior hairline approach with subcutaneous plane of dissection.

\section{IDEA}

Between May 2014 and February 2015, we removed forehead osteomas from three female patients (30, 42, and 60 years old) between May 2014 and February 2015. These masses had been growing for 3 to 15 years (Table 1). None of the patients had ever been exposed to trauma, nor did they have associated symptoms such as headache, tenderness, and hypoesthesia. Each patient had presented to the hospital with the chief complaint being palpable mass. The size and location of osteomas were confirmed by preoperative computed tomography (CT) scan (Fig. 1). Each patient wished to have the respective tumor removed without leaving a 
prominent forehead scar, and thus the option of anterior hairline approach was offered and accepted.

\section{Operative technique}

Upon general anesthesia, a 1\% lidocaine with 1:100,000 epinephrine mixture was injected into the anterior hairline incision site. This tumescent injection was extended into the forehead for hemostasis and hydrodissection. The incision was designed along the anterior hairline to temporal crests on both sides (Fig. 2). The incision was performed in the orientation of hair follicles, using a No. 15 blade. After incision was extended down to the subcutaneous fat layer, the dissection was carried in this plane towards the

Table 1. Patient demographic and clinical details

\begin{tabular}{llllll} 
Case & Age (yr)/sex & $\begin{array}{c}\text { Tumor size } \\
(\mathrm{cm})\end{array}$ & $\begin{array}{c}\text { Operation } \\
\text { time }\end{array}$ & $\begin{array}{c}\text { Complication } \\
\text { Follow-up } \\
(\mathrm{mo})\end{array}$ \\
\hline 1 & $30 /$ Female & $3.5 \times 4$ & $3 \mathrm{hr} 30 \mathrm{~min}$ & None & 12 \\
2 & $42 /$ Female & $2.3 \times 0.5$ & $1 \mathrm{hr} 30 \mathrm{~min}$ & None & 12 \\
3 & $60 /$ Female & $1.5 \times 1.2$ & $1 \mathrm{hr} 20 \mathrm{~min}$ & None & 6 \\
\hline
\end{tabular}

site of osteoma. With the dissection completed, the frontalis muscle and periosteum were incised parallel to the course of supraorbital nerve (Fig. 3). The exposed osteomas were freed with a burr drill and removed using an osteotome. The resultant bony defect was re-contoured using a Medpor ${ }^{\circledR}$. Drains were not placed. Upon adequate hemostasis, the subcutaneous fat layer was closed with 4-0 PDS sutures. Gauze and bandage were used as compressive dressing. The surgical staples were removed on the 7 th day after surgery.

\section{DISCUSSION}

Benign tumors commonly found on the forehead include lipoma, dermoid cyst, epidermal cyst, and osteoma [1]. Among these, osteomas occur with frequency in the skull vault and facial skeleton [3]. The frontal sinus is the most frequent location of cranial osteomas [4]. Osteomas are known to keep growing and metastasize to nearby tissue. In general, patients most frequently present with this bony lesion in the third and fourth decade of life, and male
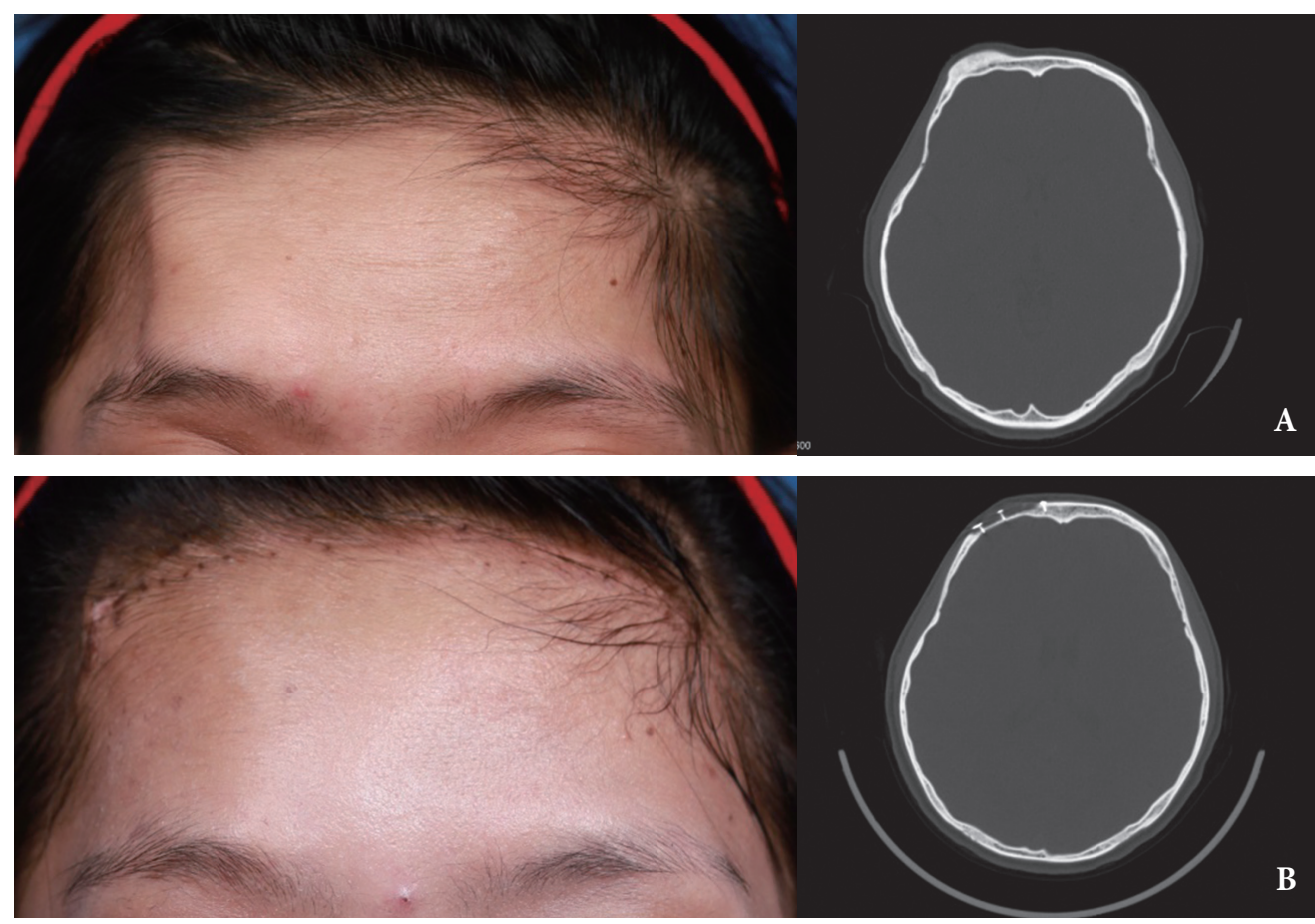

Fig. 1. Case 1. Preoperative photograph and computed tomography (CT) scan of a 30-year-old female with a lager right-sided forehead osteoma (A). Postoperative photograph and CT scan at 3-months show a well healing wound that is easily hidden in the hairline and improved contour of the forehead (B). 

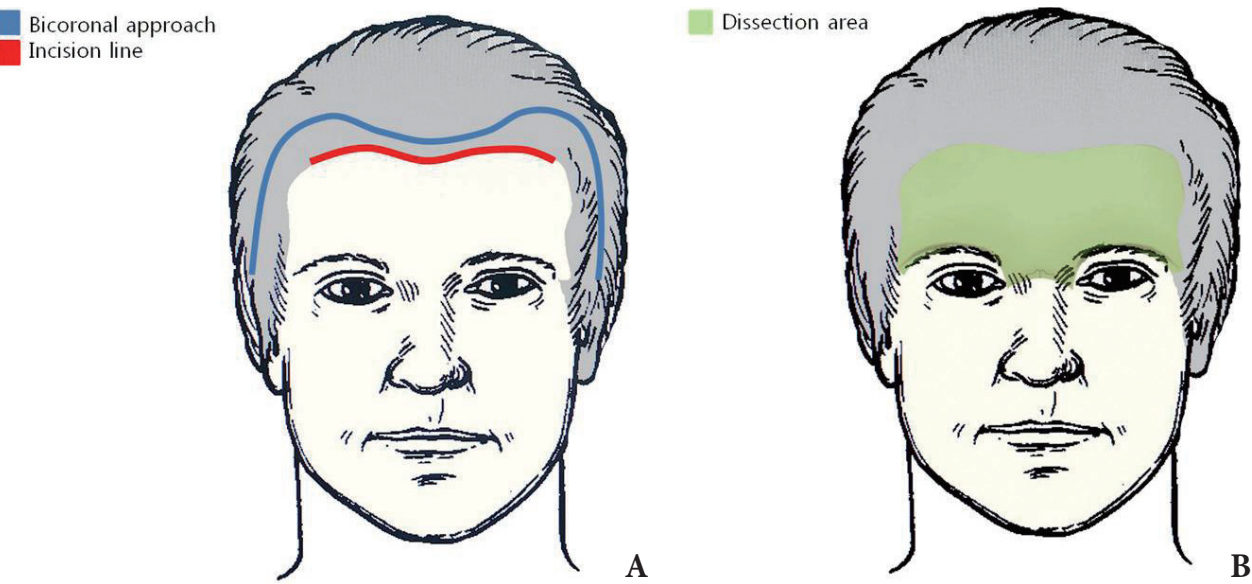

Fig. 2. (A) Incision lines for bicoronal incision and anterior hairline incision. (B) The dissection area. The forehead is elevated in the subcutaneous plane. Because the resulting flap is thin and pliable, the supraorbital rim area can be accessed through a much smaller incision.
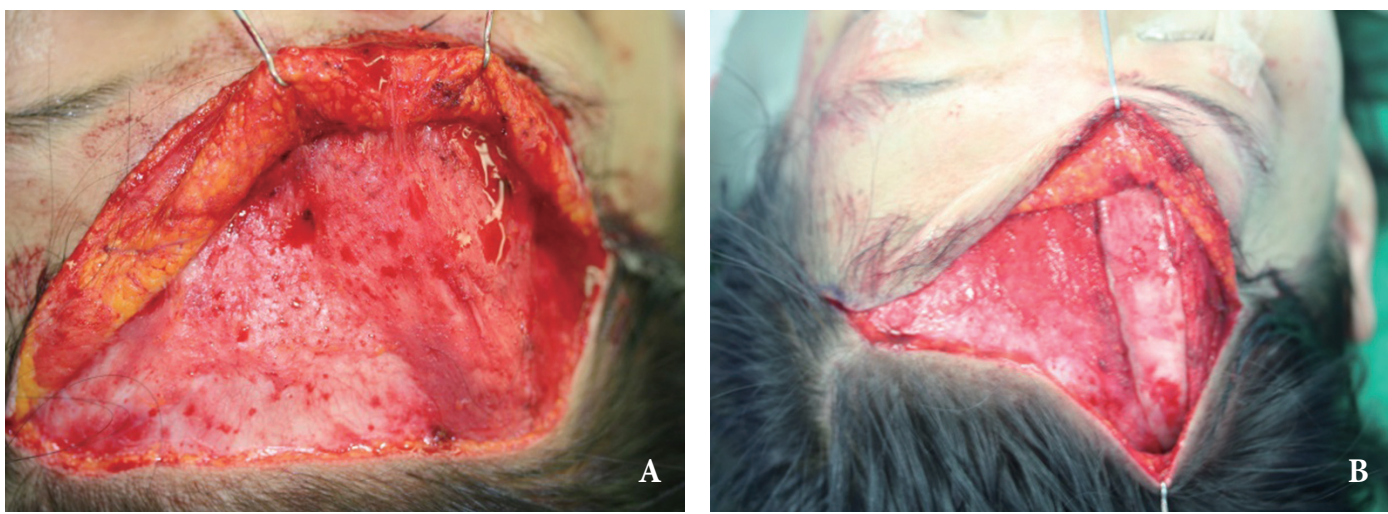

Fig. 3. Case 1. (A) Intraoperative view of subcutaneous dissection. (B) The frontalis muscle and periosteum is incised parallel to the course of supraorbital nerve.

are affected somewhat more frequently.

In the absence of symptoms, there is no need to remove osteomas by surgery. However, it is necessary to remove osteomas to preserve major organs and for aesthetic purposes. Also, frontal osteomas are indicated for resection if accompanied by symptoms, block frontal sinus drainage, account for more than $50 \%$ of the frontal sinus volume, when continued growth is evident in Xray examinations, or if the growth affects the sphenoidal sinus [5]. In our three patients, surgical resection was offered because of the aesthetics and also because of the history of continued growth.

Although direct skin incisions are appropriate for small tumors, the coronal approach or endoscopic surgery is commonly used when the tumors are large and conspicuous scars are unacceptable. Endoscopic surgery has the advantage of leaving a small scar, but is associated with increased risk of damage to facial or sensory nerves. This minimally-invasive approach is not appropriate for incising large tumors $[2,6]$. The bicoronal incision is useful for accessing the upper and middle facial bones, including the zygomatic arch. This approach provides excellent visualization of the surgical site and allows the incisional scar to be hidden behind the hairline. In addition, extension of the incision down to the preauricular area allows exposure of the entire orbit [7]. However, this extended approach can lead to injury of the temporal branch of the facial nerve, if the operator is not experienced in distinguishing between the superficial and deep layers of the deep temporal fascia. Bicoronal approach may cause temporary dysesthesia of posterior incision, temporary hair loss at the incision site, and complications that include injury to the temporal branch of the 
facial nerve when extending the incision to the front of tragus [8].

The supraorbital nerve exits the frontal bone through the supraorbital foramen before dividing into two branches. The superficial branch of the supraorbital nerve courses over the surface of frontalis muscle to provide sensation to the central forehead. The rest of the scalp and top of the head are innervated by the deep branch, which travels laterally between the periosteum and galea. The deep branch runs in a $1 \mathrm{~cm}$-wide band medial to the palpable temporal crest line and innervates the frontoparietal scalp [9]. Because of this anatomy, subgaleal dissection may cause permanent forehead numbness or hypoesthesia [1]. In order to prevent this potential complication of the subgaleal dissection, we removed forehead osteomas through an anterior hairline incision and subcutaneous plane of dissection. During follow-up periods ranging from 6 to 12 months, no complications were noted, such as facial nerve paralysis, forehead hypoesthesia, infection, and hematoma. This procedure provides a couple of advantages for avoiding scar formation. First, the anterior hairline approach requires incision line shorter than that of the conventional bicoronal approach. Second, the incision line is not straight but curved. Hence, the scar is less visible due to camouflage effect.

Despite the small number of cases, our experience with the anterior hairline incision and subcutaneous dissection has been encouraging. The method allowed us to remove relatively large osteomas without injury to the nerve branches that traverse the forehead tissue. Aesthetic outcomes were excellent. This method provides access to a wide sections of the forehead through a relatively small incision because the elevated flap by subcutaneous dissection is more thin and pliable than the conventional method.

\section{REFERENCES}

1. Jung ES, Pyon JK, Mun GH, Oh KS. Endoscopic excision of forehead masses. J Korean Cleft Palate-Craniofac Assoc 2004;5:141-6.

2. Steele MH, Suskind DL, Moses M, Kluka E, Liu DC. Orbitofacial masses in children: an endoscopic approach. Arch Otolaryngol Head Neck Surg 2002;128:409-13.

3. Lee HJ, Shin MS, Park BY, Lim SY, Pyon JK, Bang SI, et al. Multiple osteomas in the skull vault: case report. J Korean Soc Plast Reconstr Surg 2011;38:512-5.

4. Haddad FS, Haddad GF, Zaatari G. Cranial osteomas: their classification and management: report on a giant osteoma and review of the literature. Surg Neurol 1997;48:143-7.

5. Savic DL, Djeric DR. Indications for the surgical treatment of osteomas of the frontal and ethmoid sinuses. Clin Otolaryngol Allied Sci 1990;15:397-404

6. Mun GH, Jung ES, Lim SY, Hyon WS, Bang SI, Oh KS. Excision of forehead osteomas: experience with 12 patients with use of an endoscopic technique. J Craniofac Surg 2006;17:426-30.

7. Chang SC, Chen PK, Chen YR, Chang CN. Treatment of frontal sinus osteoma using a craniofacial approach. Ann Plast Surg 1997;38:455-9.

8. Shin JY, Roh SG, Lee NH, Yang KM. A case report in treatment of the frontal sinus osteoma using cranial bone graft. J Korean Soc Plast Reconstr Surg 2010;37:309-12.

9. Rodriguez ED, Losee JE, Neligan PC. Craniofacial, head and neck surgery, pediatric plastic surgery. In: Neligan PC, Rodriguez ED, Beek AL, Losee JE, editors. Plastic surgery. 3rd ed. London: Elsevier/Saunders; 2013.p. 107-8 